\title{
A comparison of the loneliness levels of Turkish university students in terms of Internet use
}

\author{
Şuheda ÖZBEN \\ Dokuz Eylul University, Buca Faculty of Education, Educational Sciences Department, Izmir, Turkey
}

Email address:

suheda.ozben@deu.edu.tr

To cite this article:

Şuheda ÖZBEN. A Comparison of the Loneliness Levels of Turkish University Students in Terms of Internet Use. Psychology and Behavioral Sciences. Vol. 2, No. 3, 2013, pp. 112-116. doi: 10.11648/j.pbs.20130203.15

\begin{abstract}
The objective of this research was to compare the loneliness levels of Turkish university students in terms of Internet use. This was a descriptive and comparative study involving a total of 525 students in Izmir, 258 female and 267 male, who participated voluntarily. The instruments were the personal information form and the UCLA loneliness scale, and a t-test was use to compare the data. The results revealed that loneliness points were significantly higher for students who preferred the Internet rather than being with friends $\left(t_{519}=6.013, p=.001\right.$ and those who preferred social chats online rather than their actual friends $\left(t_{519}=5.666, p=.001\right)$. The loneliness level was higher for those who cannot postpone their Internet use $\left(t_{520}\right.$ $=1.704, p=.089)$ and those who could not give up Internet use $\left(t_{521}=.126, p=.900\right)$; however, a significant relationship was not found. This study reiterates the importance of Internet use or online computer hours for students, and the importance of media literacy training. To cope with loneliness, students need to bond with their peers, establish more fulfilling relationships, and develop their social skills. Schools on should place importance social skills training, effective communication skills, and art and cultural activities. It is essential to have some strategies to prevent Internet addiction.
\end{abstract}

Keywords: University Student, Internet Use, Loneliness

\section{Introduction}

Internet use has spread rapidly throughout the world. Internet is a term meaning various online functions, such as the World Wide Web (www), chat rooms, interactive games, news groups, or database search engines [1]. The advantages of the Internet in comparison with other media tools are universal availability to the entire world, ease of access from anywhere, and rapid source for breaking news [2]. It has been a quick and cheap communication and sharing instrument, and it meets people's communication needs.

According to the results of Research on Information Technologies Use by Households in Turkey, carried out by the Turkish Statistical Institution, the rate of households that have Internet access is $47 \%$. The age group with the highest computer and Internet use rate is $16-24$ years. This rate is higher than the total rate of male users from all age groups. Most Internet users (73\%) use the Internet to read online news, newspapers, or magazines, and to download news. This is followed by e-mail (67\%); searching for information on goods and services (61\%); and game, music, and image download (49\%). The rate of Internet users who order or purchase goods and services for personal use is $22 \%$. It has been reported that the rate of Internet use for connecting with public institutions for personal purposes is $45 \%$ [3]. All of these are conveniences provided by computer and Internet use, the importance of which cannot be disregarded, and the Internet has become an indispensable part of daily life.

Computer and Internet addiction is a technological addiction. Technological addictions are operational, non-chemical (behavioral) addictions that include human-machine interaction [4].

Today, Internet addiction is identified with terms such as "Internet addiction disorder," "pathological Internet use", "problematic Internet use", and "compulsive Internet use".

Young (1996) determined the criteria of Internet addiction by applying pathological gambling criteria, and considered fulfillment of five of the eight criteria sufficient to satisfy a diagnosis of Internet addiction. These criteria are as follows:

1. Excessive mental occupation related to Internet use (constantly thinking of the Internet, dreaming about Internet activities, thinking about the next activity planned to be made on the Internet, etc.);

2. Increasing need for Internet use;

3. Unsuccessful attempts towards controlling, decreasing, or totally giving up Internet use; 
4. Feeling anxious, depressed, or angry when Internet use is decreased or given up;

5. Using the Internet more than the planned period, having problems at school, with family, in the workplace, and among friends due to excess Internet use;

6. Putting educational or career-related opportunities at risk or losing them;

7. Lying to others (family, friends, therapist, etc.) about the duration of Internet use;

8. Using the Internet to avoid problems or negative feelings (despair, guilt, depression, anxiety, etc.) [5].

\subsection{Problems Arising from Problematic Internet Use}

Problematic Internet use is a multidimensional syndrome consisting of cognitive and behavioral symptoms resulting in negative social and academic/professional results [6]. Although the Internet is a beneficial research tool, students visit unrelated websites, chat in chat rooms, chat with Internet friends, and play interactive games. All of these have been determined to impact study habits of students and result in a significant decrease in their academic performance [1]. It was determined that as the Online Cognition Scale score increased, students' performance of Internet activities such as general information searches and academic research decreased, and that performance of interactive and entertainment Internet activities such as chat, financial transactions, game playing, sex, downloading programs, and listening to MP3s increased [7]. Furthermore, a significant relationship has been found between problematic Internet use and social interaction anxiety [8].

Over use of the Internet primarily causes health problems in users. These problems are eye fatigue, head, back, and waist aches, physical inactivity, fatigue, insomnia, deterioration of the skeleton, risk of radiation, and impairment of the immune system. Over use of the Internet causes psychosocial problems in addition to health problems. Marriages, friendships, parent-child relationships, and close friendships are seriously damaged, and the addicted spare less time for the people around them. Individuals start to establish "online" relationships that overshadow time spent with people in real life [1]. Internet addiction leads to a decrease in psychosocial wellbeing for adults [9].

\subsection{Relationship between Internet Use and Loneliness}

Loneliness is the absence of social relationships required by a person, or the absence of intimacy, sincerity, and sensuality despite having various social relationships. According to Weiss, there are two different types of loneliness. In social isolation (alienation), one is dissatisfied and lonely because of the lackof a social network of friends and acquaintances. In emotional isolation (being unattached), one is dissatisfied and lonely because one lacks a single intense relationship [10]. Loneliness is a negative emotion resulting from the perception of deficiencies by individuals with relation to their personal relationships, such as feelings of unpleasantness, avoidance, sorrow, and bitterness; it occurs when there are significant quantitative and qualitative deficiencies in an individuals' social relations network [11, 12].

A positive correlation has been found between Internet use and loneliness [6,9-15, 22].

Individuals who have psychosocial problems prefer online interaction to face-to-face talking [23]. Lonely people use the Internet mostly for communication purposes. Spending too much time on the internet leads people into loneliness, it tears individuals from the social environments they belong to, it weakens their relationships with family and friends and that individuals behave much easier on virtual communication than they do in real life [21].University students who are in the period of young adulthood are in need of developing close relationships. During this period, the inability to establish healthy relationships causes isolation of the individual from the social environment and leads to the development of loneliness [24]. Internet addiction is a bigger problem among university students. Being away from home, using spare time badly, and use of the Internet for educational reasons are listed as some of the reasons for increased risk for addiction in this group [9]. With perceived loneliness, the individual may prefer Internet use and chatting with online friends to establishing close relations.

Lonely students have stated that they have problems such as making friends, introducing themselves, joining groups, enjoying parties, and making phone calls to initiate social activities [25]. Such results may prevent compatible transition to adulthood and endanger psychological well-being. In particular, preference for virtual communication via the Internet may cause university students, who have a high tendency for Internet use, to experience loneliness. Together with loneliness, psychological problems such as depression, anxiety, and stress, which threaten mental health, also occur. Therefore, the issue is of great importance and a focus of attention in terms of appropriate media use. In this study, we focused on Internet use and loneliness of university students.

The objective of this study was to compare loneliness levels of Turkish university students in terms of Internet use.

Research questions were:

1. Is there a statistically significant difference between loneliness levels of university students in terms of preferring the Internet rather than being with friends?

2. Is there a statistically significant difference between loneliness levels of university students in terms of preferring social chats online rather than their actual friends?

3. Is there a statistically significant difference between loneliness levels of university students in terms of postponing their Internet use?

4. Is there a statistically significant difference between loneliness levels of university students in terms of giving up Internet use? 


\section{Main Body}

\subsection{Methods}

\subsubsection{Sample}

The sample of students was randomly selected and all of them participated voluntarily. Participants were 525 single (unmarried) university students from different universities in İzmir, Turkey. There were 258 females (49\%) and 267 males (51\%). The mean age of the participants was $21.58(S D=$ $1.85)$ years.

\subsubsection{Instruments}

The UCLA Loneliness Scale (UCLA-LS) was used. This scale, developed by Russell, Peplau, and Ferguson (1978) and later revised by Russell, Peplau, and Cutrona (1980), is used to measure general loneliness levels. It is a 20 -item Likert-type self-report inventory in which participants indicate on a 4-point scale how often their feelings coincide with the given statement $(1=$ never, $2=$ rarely, $3=$ sometimes, $4=$ often) $[23,10]$. Russell et al. (1980) gained a high level of internal consistency (reliability) for the instrument, with a Cronbach's alpha coefficient of .94. The Turkish adaptation of the scale was developed and compared by Demir (1989), who gained an internal consistency coefficient of .96 and a test-retest reliability coefficient of .94 [27]. The parallel form validity of the UCLA-LS (Demir, 1989) was tested with the Beck Depression
Inventory (Beck, Ward, Mendelson, Mock, \& Erbaugh, 1961) and the correlation coefficient was .77. In this study, Cronbach's alpha coefficient for internal consistency was .89 .

Personal Information Form: This form includes gender, age, and four questions.

\subsubsection{Process}

This study was a descriptive study in which the participants' existing loneliness levels were determined by the UCLA Loneliness Scale and Personal Information Form, and then these were analyzed according to research questions.

\subsubsection{Analysis of Data}

Descriptive statistics were used to identify the mean values of the answers. The difference between the means of the UCLA Loneliness Scale in terms of participants' answers to the questions "yes" or "no" were analyzed by independent samples $t$-test. Statistical analyses were performed by using SPSS for Windows 13.00. A significance level of .05 was accepted.

\section{Results and Discussion}

The results of the independent samples $t$ tests that were used to determine the differences between loneliness levels of university students can be seen in Table 1 .

Table 1. Comparison of the loneliness levels of university students in terms of Internet use

\begin{tabular}{|c|c|c|c|c|c|c|c|}
\hline Variables & Answer & $n$ & $M$ & SD & $t$ & $D f$ & $p$ \\
\hline \multirow{2}{*}{$\begin{array}{l}\text { Preferring the Internet rather } \\
\text { than being with friends. }\end{array}$} & Yes & 54 & 44.24 & 10.54 & \multirow[t]{2}{*}{6.013} & \multirow{2}{*}{519} & \multirow{2}{*}{$.001^{*}$} \\
\hline & No & 467 & 36.75 & 8.43 & & & \\
\hline \multirow{3}{*}{$\begin{array}{l}\text { Preferring social chats online rather } \\
\text { than their actual friends }\end{array}$} & Yes & 33 & 45.82 & 11.01 & \multirow[t]{2}{*}{5.666} & \multirow{2}{*}{519} & \multirow{2}{*}{$.001^{*}$} \\
\hline & No & 488 & 36.95 & 8.53 & & & \\
\hline & Yes & 117 & 38.76 & 9.28 & \multirow[t]{2}{*}{1.704} & \multirow{2}{*}{520} & \multirow{2}{*}{.089} \\
\hline Inability to postpone Internet use & No & 405 & 37.16 & 8.83 & & & \\
\hline \multirow{2}{*}{ Inability to give up Internet use } & Yes & 237 & 37.56 & 9.29 & \multirow[t]{2}{*}{.126} & \multirow{2}{*}{521} & \multirow{2}{*}{.900} \\
\hline & No & 286 & 37.46 & 8.68 & & & \\
\hline
\end{tabular}

The aim of this research was to compare loneliness levels of Turkish university students in terms of Internet use. Four major findings emerged from this study.

First, the mean of the loneliness points of the students who answered "yes" to the first question was $M=44.24$, students who answered "no" was $M=36.75$. Loneliness levels have been found to be significantly higher for students who prefer the Internet rather than being with friends $\left(t_{519}=6.013, p=.001\right)$. These findings support those of previous studies $[6,9-15,22]$. It is obvious that loneliness mostly resulted from lack of human relationships. For students, going on the Internet in their spare time comes first; being with friends and companions comes second [2]. Preferring Internet friendships to real friendships increases loneliness of youngsters. However, individuals who experience loneliness use the Internet to share their feelings of loneliness, and problematic Internet use leads people towards more loneliness over time [20]. University students who are addicted to the Internet are lonelier than those who are not addicted [7-16, 19]. Children and youngsters who spend a lot of time on the Internet become lonelier day by day and have difficulty establishing face-to-face relationships [16].

Second, the mean of the loneliness points of the students who answered "yes" to the second question was $M=45.82$, students who answered "no" was $M=36.95$. Loneliness levels have been found to be significantly higher for students who prefer social chats online to seeing their actual friends $\left(t_{519}=5.666, p=.001\right)$.

This result can be explained by means of certain characteristics of lonely people. Lonely people cannot express themselves or engage in self-disclosure [12]. They experience difficulty in making friends, sharing feelings, and having social communication. Therefore, they may prefer 
chatting with Internet friends. There are studies available that support these research results. It has been demonstrated that university students with low self-worth are lonely and prefer establishing social relationships on the Internet to having face-to-face communication [6]. Online social interaction may be preferred due to the fact that it is less stressful compared to face-to-face contact [23]. The fact that individuals who have deterrent manners in interpersonal relationships (such as teasing others, becoming angry easily) suffer problems in social relationships may lead them to use the Internet more [19]. It has been concluded that virtual chat rooms have acted as a significant means for sharing feelings of loneliness, and the addictive effect of such actions drives individuals into more loneliness over time [21].

Third, the mean of the loneliness points of the students who answered "yes" to the third question was $M=38.76$, students who answered "no" was $M=37.16$. The loneliness level was higher for those who cannot postpone their Internet use $\left(t_{520}=1.704, p=.089\right)$; however, the difference was not significant.

Fourth, the mean of the loneliness points of the students who answered "yes" to the forth question was $M=37.56$, students that answered "no" was $M=37.46$. The loneliness level was higher for those who could not give up Internet use $\left(t_{521}=.126, p=.900\right)$. However, there was no significant difference between them.

Such results can be explained by the assertion that those addicted to the Internet use it mostly for interaction purposes; moreover, it is thought that Internet addiction provides the user with artificial and temporary feelings, such as security or serenity, self-worth or success, power and control, and intimacy or belonging $[19,1]$. The Internet may be used as a defense mechanism in order to cope with loneliness. Therefore, Internet users cannot avoid this action and cannot give up its use.

As mentioned before, it has been established that there is a significant relationship between loneliness and various psychological problems, such as depression, anxiety, introversion, lack of assertiveness, desperation, low rate of social risk taking, aggression, low self-respect, and stress $[13,14]$. In another study, neuroticism, extraversion, psychoticism, and lying were also found to be meaningful predictors for problematic Internet use [9]. According to these results, individuals go through serious psychological problems due to excessive usage of the Internet. Furthermore, the excessive use of the Internet results in many problems related to health, communication, and time by influencing both the academic and personal development of the individual in a negative way. It may also make the individual addicted [20].

Moreover, it has been observed in this research that there are significant differences between loneliness and Internet use. In these cases, the mental health of the individual can be threatened due to Internet use as well as loneliness.

\section{Conclusion}

In conclusion, this study reiterated the importance of Internet use or online computer hours for students and explains why media literacy training is important. Media literacy (also known as media education) is the process of becoming selective, wise, and critical media consumers [28]. Media education can be taught to children and youngsters so that they may behave more consciously.

Developing healthy human relationships can decrease problems related to loneliness. To cope with loneliness, students need to bond with their peers, establish more fulfilling relationships, and develop their social skills. Schools should place importance on social skills and self-disclosure training, effective communication skills, and art and cultural activities. It is essential to take some measures to prevent Internet addiction. These results can be beneficial for parents, trainers, and psychological consultants.

This study was based on field work in order to determine the correlation between loneliness and computer and Internet use. By means of the data I obtained, I hope to contribute to the relevant literature.

There are some limitations to the current study. First, the sample was restricted to university students in İzmir, so the results may not be generalizable to all Turkish university students. Further research should be carried out with groups more representative of all university students in Turkey. The second limitation was the variables of the research, which were Internet use and loneliness. Future studies may be designed using different psychosocial variables.

\section{References}

[1] Young KS. (1999) Internet Addiction: Symptoms, Evaluation, and Treatment. In: VandeCreek, L., Jackson, T. eds. Innovations in Clinical Practice: A Source Book. Sarasota, FL: Professional Resource Press. 17. pp. 19-31.

[2] Toruk I. An Analysis of the Media Usage Habits of the University Students. Selçuk University, Journal of Institute of Social Sciences 2008; 19: 475-488.

[3] Turkey Statistical Institute, ICT Usage Survey on Household in Turkey. Ankara: TSI Newsletter, 16/08/2012, -1088010.

[4] Griffiths M. Internet Addiction: Fact or Fiction? The Psychologist 1999; 12(5): 256-250.

[5] Young KS. Internet Addiction: The Emergence of a New Clinical Disorder. CyberPsychology and Behavior 1996; 1(3): 237-244.

[6] Caplan SE. A Social Skill Account of Problematic Internet Use. Journal of Communication 2005; 55(4): 721-736.

[7] Özcan NK, Buzlu S. Internet Use and Its Relation with the Psychosocial Situation for a Sample of University Students. CyberPsychology \& Behavior 2007; 10(6): 767-772. DOI: 10.1089/cpb.2007.9953. 
[8] Çuhadar C. Exploration of Problematic Internet Use and Social Interaction Anxiety among Turkish Pre-service Teachers. Computers \& Education 2012 DOI:org/10.1016/j.compedu.2011.12.029.

[9] Serin Bulut N. An Examination of Predictor Variables for Problematic Internet Use. TOJET: The Turkish Online Journal of Educational Technology 2011; 10(3): 54-62.

[10] Weiss RS. (1973) Loneliness: The experience of emotional and social isolation, Cambridge. MA: MIT Press.

[11] Peplau LA, Perlman D. (1982) Perspectives on loneliness. In LA Peplau and D Perlman eds. Loneliness: A Sourcebook of Current Theory, Research and Therapy. New York: Wiley Interscience.

[12] Perlman D, Peplau LA. (1984) Loneliness research: a survey of empirical findings. In LA Peplau \& S Goldston eds. Preventing the Harmful Consequences of Severe and Persistent Loneliness. U.S. Government Printing Office, DDH Publication No. (ADM) 84-1312. pp. 13-46.

[13] Russell D, Peplau LA, Cutrona CE. The Revised UCLA Loneliness Scale: Concurrent and Discriminant Validity Evidence. Journal of Personality and Social Psychology 1980; 39(3): 472-480.

[14] Jones WH, Freemon JE, Goswick RE. The Persistence of Loneliness: Self and Other Determinants. Journal of Personality $1981 ; 49(1)$ : 27-48.

[15] Kraut R, Patterson M, Lundmark V, Kiesler S, Mukophadhyay T, Scherlis W. Internet Paradox: A Social Technology that Reduces Social Involvement and Psychological Well-being?. American Psychologist 1998; 53(9): 1017-1031.

[16] Morahan-Martin J, Schumacher P. Incidence and Correlates of Pathological Internet Use Among College Students. Computers in Human Behavior 2000; 16:13-29.

[17] Kubey RW, Lavin MJ, Barrows JR. Internet Use and Colligate Academic Performance Decrements: Early Findings. Journal of Communication 2001; 51: 366-382. DOI/10.1111/j.14602466.2001.

[18] Davis RA. A Cognitive-Behavioral Model for Pathological Internet Use (PIU). Computers in Human Behavior 2001; 17(2): 187-195
[19] Durak Batıgün A, Hasta D. Internet Addiction: An Evaluation in terms of Loneliness and Interpersonal Relationship Styles. Anatolian Journal of Psychiatry, 2010; 11(3), 213-219.

[20] Çağır G, Gürgan U. The relationship Between the Levels of High School and University Students' Problematic Use of Internet and Their Perceived Wellness and Loneliness Levels. Ballkesir University, Journal of Institute of Social Sciences, 2010, 13(24): 70-85

[21] Özen Ü, Sarıcı Korukcu MB. Being Lonely and the Effect of Virtual Chat on Sharing of Loneliness: A Study on the University Students. Atatürk University, Journal of Faculty of Economics and Administrative Sciences 2010; 24(1):149-159.

[22] Stepanikova I, Nie NH, He X. Time on the Internet at Home, Loneliness, and Life Satisfaction: Evidence from Panel Time-Diary Data. Computers in Human Behavior 2010; 26 : 329-338 DOI:10.1016/j.chb.2009.11.002.

[23] Caplan SE. Theory and Measurement of Generalized Problematic Internet Use: A Two-Step Approach. Computers in Human Behavior 2010; 26:1089-1097 DOI: 10.1016/j.chb.2010.03.012

[24] Ericson E. (1963) Childhood and society (2nd ed.). New York: WW Norton.

[25] Horowitz LM, French Anderson CA. (1982) the Prototype of a Lonely Person. In: Peplau, LA and Perlman, D, eds. Loneliness: A Sourcebook of Current Theory, Research and Therapy. New York: Wiley-Interscience.

[26] Russell D, Peplau LA, Ferguson ML. Developing a Measure of Loneliness. Journal of Personality Assessment 1978; 42 (3): 290-294.

[27] Demir A. Reliability and validity of UCLA loneliness scale. Turkish Journal of Psychology 1989; 7:14-18.

[28] Hogan MJ. (2001) Parents and Other Adults: Models and Monitors of Healthy Media Habits. Singer D. Singer J. Handbook of Children and the Media Thousand Oaks (CA): Sage Publications, 663-680. 